\title{
Uso, abuso y desgastede la expresión "Libertad de expresión" en Chile: Genealogía y crítica
}

Es increíble lo que se puede hacer en nombre de las libertades. Se pueden lanzar misiles contra civiles, se puede embargar un país y bombardearlo en nombre de las libertades. Evidentemente se puede también liberar pueblos y hacer justicia y, por esa distancia infinita, es que libertad, a decir de Sartori, es uno de los conceptos más equívocos y esquivos de nuestra historia moderna. Ya ha dicho mismo Sartori que la nuestra es una época de la "confusión democrática", en el comienzo de su excelente Democracy Theory, de 1983: "hasta los años cuarenta de este siglo existía una clara idea en políticos y ciudadanos de qué era la democracia. Había quienes la defendían y también quienes la atacaban por considerarla insuficiente o defectuosa. Cada quien con sus argumentos (...) Hasta entonces los regímenes comunistas y fascistas no pretendían pasar por democráticos. Ellos se justificaban, precisamente, en la crítica de la democracia "burguesa" o "representativa" y pretendían superarla". Lo mismo puede aplicarse al concepto de libertad, imbuido en la maquinaria narrativa de la democracia.

En las páginas que siguen nos abocaremos a la libertad de expresión en Chile. Sin embargo, valga desde un comienzo las aclaraciones: nos interesa esa dimensión de la libertad de expresión propiamente genealógica. La manera habitual en que la libertad de expresión es tratada - esto es, bajo un alo moral, político o jurídico - nos importa tan sólo en la medida de que es sometible a un discurso deconstructivo. En consecuencia, la entrada a nuestro objeto intenta esquivar la inmediatez del concepto, ponerla en entre dicho como categoría moral, para someterla a las dinámicas constituyentes del relato, de la narrativa.

El uso redundante implica, como apunta Derrida a propósito del "uso de la metáfora", una forma particular de desgaste, de agotamiento, que en el caso particular de la libertad de expresión hace casi inseparable el conjunto de palabras que forman el concepto[1]. Podríamos decirlo en otros términos, en términos más foucaultianos: la libertad de expresión constituye un enunciado. Enunciado como conjunto de términos interrelacionados que forman parte constituyente de un orden discursivo, de una categoría enunciativa[2]. Libertad - de expresión como un enunciado indisociable, como una frase - palabra.

En los últimos treinta años la libertad de expresión (podemos referirnos a ella ya casi como un sustantivo personal) se ha transformado en una palabra (des) gastada, usada hasta el hueso: los estudios en comunicación la han vuelto objeto de análisis; el derecho, en su estricta terminología, la ha puesto como tema capital en la legalidad contemporánea; la prensa, los partidos políticos, los artistas, las agencias publicitarias[3], organizaciones no gubernamentales, los ciudadanos comunes y silvestres...la lista podría agotarse cuando se agoten las dimensiones de nuestra sociedad.

El uso de la libertad de expresión la convierte en un usual: libertad de expresión es un concepto usual. Cotidiano, transversal a todo tipo de práctica comunicacional, sea en las esferas más elevadamente ilustrada a las más pobremente legas. Que a lo largo del tiempo una palabra adquiera un sentido usual (casual, dirían los más suspicaces), no sólo manifiesta su gasto, su redundancia, su sobre abundancia: también la convierte en acervo del sentido común.

Y concientes somos de los peligros del sentido común: éste borra a menudo los rasgos más propiamente históricos de los objetos. Tendemos a olvidar la composición original de esos fósiles gastados hasta la miseria y tendemos a creer, como agudamente señala Heidegger, que aquellos forman parte de lo que está "a la mano"[4]. Lo cotidiano, lo usual, es lo propiamente irreflexivo. Lo cotidiano se vive, no se piensa. La libertad de expresión 
pertenece a ese mundo de enunciados cotidianos, usados, a la mano para todo y para todos. Dirá Heidegger: "(en) este modo de trato que es el uso, la ocupación se subordina al para algo que es constitutivo del respectivo útil: cuanto menos sólo se contemple la cosa martillo, cuanto mejor se eche mano del martillo usándolo, tanto más originaria será la relación con él". Podríamos decir lo mismo de la cosa - libertad de expresión: cuanto menos se contempla ésta, tanto más se vuelve uno de esas cosas de uso cotidiano.

Pero he aquí que dejamos las alturas y entramos en arenas más pantanosas: la otra cara del uso es, como señala Heidegger, la dimensión de utilidad del enunciado. La libertad de expresión es un enunciado usado, como dijimos, relacionándolo con esa constelación de términos adyacentes: desgastado, gastado, usual, cotidiano. Agreguemos ahora otro más: la libertad de expresión es un enunciado utilizado. A simple vista no decimos nada nuevo, pues la pareja usar - utilizar serían sinónimas. Pero echemos otra mirada. El uso implica una relación pasiva entre el sujeto y el objeto. Podríamos decir, una relación inocente, no necesariamente instrumental. Yo puedo usar un pan para martillar, pero el pan no me es útil para martillar. Para martillar me es más útil el martillo.

En otras palabras, toda cosa utilizada es a la vez usada, pero no toda cosa usada es útil para un fin específico. Aquellas cosas que nos son útiles para obtener determinados fines las llamamos instrumentos. Lo que esas cosas hacen es cumplir una determinada función.

Del mismo modo, la presencia usual de la libertad de expresión dentro de nuestra sociedad oculta esa dimensión de utilidad para con el sistema social pues podemos referirnos a la libertad de expresión como dispositivo (en el sentido que le da Foucault al término), sutil mecanismo que cumple funciones precisas dentro del orden actual de Chile. Podría fácilmente achacar a esta afirmación el retorno a la manida idea de dominación marxista; o la teoría de la ideología dominante, de la hegemonía de clases, tal y como la entendía Gramsci[5]; sin embargo, creo que la principal diferencia entre la tesis marxista clásica de la dominación y la que aquí intento sostener, es que no todo enunciado es útil en el sistema: el modo particular de saludo de un grupo humano no necesariamente cumple una función dentro de un plexo social, así como tampoco aquellas desviaciones del lenguaje correcto o tipificado. Por el contrario, circulan en nuestra habla una infinidad de enunciados que no sólo no son parte funcional del sistema social, sino que incluso le son antagónicos. Así, por ejemplo, como sostiene Nelly Richard, el garabato y los modismos constituyen formas de resistencia de los grupos humanos locales contra los procesos de homogenización discursiva de la Globalización, impidiendo la traductibilidad, resistiendo la fácil homologación[6]. En estas tácticas y estrategias de resistencia, tal y como señala Foucault, incluso un enunciado al servicio de un sistema de dominio puede volvérsele en su contra[7].

Pero la libertad de expresión es un enunciado funcional al sistema: ¿por qué? ¿de qué manera? Desde luego, ese sitial privilegiado que ha obtenido la libertad de expresión en Chile no es gratuito: se debe a un alucinante despliegue de instalación llevado a cabo aproximadamente durante los últimos treinta años en Chile, y que culmina en los años 90 con el retorno a la democracia (el fin del principio). El dispositivo, instalado ya en nuestra sociedad, se invisibiliza: actúa como ordenador de un conjunto de valores asociados naturalmente con la democracia, la justicia y las promesas de igualdad y movilidad social impuestas por el "derecho burgués" (término olvidado). El proceso de instalación es lento, doloroso y por qué no decirlo, sangriento: se necesitó bastante poder disuasivo durante el régimen militar para que los pensadores de izquierda que hasta el fin de la Unidad Popular proclamaban unidad del pueblo en todas sus variantes, la expropiación de los medios de comunicación privados y la negación radical a las promesas del derecho burgués adoptaran como bandera propia, y antes que ningún otro sector de nuestra sociedad, el discurso de la libertad de expresión como un derecho que emana de la condición humana misma, pilar fundamental de una sociedad democrática, que necesita de medios de comunicación liberales para garantizar su imperio. Como colorario de lo anterior, la izquierda sacrifica su anhelo de unidad por su contrario (más chic para los nuevos tiempos): diversidad; en otras palabras, por sobre la clase, por sobre el pueblo unido, estará la persona, el individuo, luego la familia, los "grupos intermedios" y en orden decreciente de importancia hacia el plexo social. No se quiere decir con esto que los pensadores de izquierda despreciaron, durante y luego de la Dictadura, sus antiguos 
principios de fraternidad ni el fortalecimiento de los grupos intermedios (sindicatos, colegiados, juntas de vecinos, medios de comunicación locales, etcétera). Éstos seguían siendo vistos como importantes en el orden democrático, y estos principios eran y son considerados aún los que una marca de fábrica de la izquierda: privilegiar lo colectivo por sobre el individualismo y/o privado. El asunto es otro.

Lo que sugiero es que estos principios pierden su status privilegiado - casi sagrado - ceden su lugar a un conjunto de nuevos valores que le llegan al discurso intelectual desde afuera: la clase, la unidad social seguirá siendo importantes en él: pero si la primera atenta contra la diversidad, contra la libre expresión, contra el derecho de toda persona al "respeto y protección de la vida privada y pública y a la honra de la persona y de su familia"[8], entonces es la clase la prepotente, no es el individuo el mezquino. Y el axioma es idéntico en todos los niveles: si un subgrupo en particular es violentado por un universo social mayor, se privilegia siempre al subgrupo, y no al universo. Es la minoría la que impone su derecho a la mayoría. La libertad estaría por sobre la fraternidad.

Desde luego, nada de esto ha sido fruto de una generación espontánea. El conjunto de transformaciones profundas que nuestra sociedad ha vivido los últimos años el producto, el resultado de un lento movimiento histórico que va desde el romance nacional vivido durante la Unidad Popular pasando por los dos momentos que definen la Dictadura (La Dictadura propiamente tal y la Dictadura Constitucional desde 1980), hasta el retorno a la democracia. A lo largo del tiempo, el discurso de la izquierda comienza a adoptar un lenguaje que no le es propio de su tradición: a saber, el lenguaje del saber burgués. La izquierda, podríamos arriesgadamente adelantar, cede su poder de interpretación de la realidad. Investigando este fenómeno podemos constatar el movimiento global de la sociedad en los últimos treinta años.

Ahora bien, ¿cuál es el lugar que dentro del sentido común ocupa la libertad de expresión en nuestro país? El primero, el más evidente, remite al orden constitucional: la libertad de expresión es un derecho. A partir de esta cándida certeza, la libertad de expresión se ubica dentro de un orden discursivo jurídico - moral, dentro de una cadena enunciativa que la hermana con otros principios igual de constitutivos para el ser chileno: la igualdad, la libertad a secas, la dignidad humana...

Decreto Ley: Constitución Política de la República de Chile.

Capítulo

Art. 1: Las personas nacen libres $e$ iguales en dignidad $y$ derechos. La familia es el núcleo fundamental de la sociedad. El Estado reconoce y ampara a los grupos intermedios a través de los cuales se organiza y estructura la sociedad y les garantiza la adecuada autonomía para cumplir sus propios fines específicos.

Art. 4: Chile es una república democrática[9].Capitulo Tres: "De los Derechos y deberes Constitucionales".

Art. 19: La constitución asegura a las personas:

6: La libertad de conciencia, la manifestación de todas las creencias y el ejercicio libre de todos los cultos que no se opongan a la moral, a las buenas costumbres y al orden público.

7: El derecho a la libertad personal y a la seguridad individual.

12: La libertad de emitir opinión y la de informar, sin censura previa, en cualquier forma y por cualquier medio, sin perjuicio de responder por los delitos y abusos que se cometan en el ejercicio de estas libertades, en conformidad a la ley, la que deberá ser de quórum calificado. 
La ley en ningún caso podrá establecer monopolio estatal sobre los medios de comunicación social[10].

Se observa, en la base misma de nuestra institucionalidad, una preocupación por el tema de la libertad que está lejos de ser derivada: la libertad es la base misma sobre la cual se articula una constelación de derechos y deberes. Libertad es la primera garantía de nuestra Constitución.

No son pocos los investigadores que relacionan de manera casi instantánea la libertad de expresión con la forma de el presunto "derecho a la información" proporcionado por los periodistas[11]. Cabe destacar aquí que el asunto es mucho más complejo. La libertad de expresión relacionada con los medios de comunicación aparece recién nominada en el Capítulo Tres (Art. 19; 12) de la Constitución. No obstante, el tema de la libertad, como dijimos, surge desde el primer párrafo, y continúa resurgiendo - de manera redundante - a lo largo de todo el texto. En consecuencia, la libertad de expresión satisface necesidades sociales tan básicas y abarca posibilidades tan amplias de discusión, que delimitarla al campo del problema de los medios de comunicación constituye una riesgosa torpeza: en la sensibilidad social actual - "posmoderna", heterogénea, la de la "aldea global" - la libertad de expresión, en su particular afirmación jurídico moral, es usada en múltiples facetas.

Los artistas reclaman más libertad de expresión para cultivar sus objetos de arte: conocida es la tendencia del arte actual a ocupar los espacios públicos, a centrarse más en los efectos de su objeto que en la producción del objeto mismo; la acción de arte, la performance, desde el movimiento de arte de vanguardia de los sesenta, a acrecentado un modo de producción artística que busca la sensación, el impacto y el cuestionamiento mismo de lo que el sentido común considera arte. En esta perspectiva, muchos artistas han sido objeto de denuncias y hasta condenas por faltar a ese noble principio de respetar la moral y las buenas costumbres. Casos recientes de polémica pública como el proyecto Nautilus (2000)[12], el "Baby Vamp" (2002)[13], u otros menos conocidos como la exposición de perros disecados y modificados con fines artísticos, o el cómic que mostraba a un Arturo Prat como héroe accidental[14], o el más atrevido montaje teatral que lo caracterizaba como homosexual[15], han concertado a los artistas a reclamar por una mayor libertad de expresión, independiente del reclamo particular de los medios de comunicación.

Un uso distinto de la libertad de expresión es la que realizan los medios de comunicación. A diferencia de lo que sucede en el arte, en que la defensa de la libertad de expresión está más bien relacionada con el objeto y/o el sujeto particular de la censura, cuando se habla de libertad de expresión en los medios de comunicación se hace referencia a un derecho "social", esto es, aquel que constituye a los medios como entidades consustanciales a la formación de la opinión pública y de cumplir con el derecho a la información[16]. En particular los periodistas, debido a la multiplicad de acontecimientos que han llevado a la censura de ciertos textos y al encarcelamiento o exilio de algunos profesionales (el caso más representativo es la censura de El Libro Negro de la Justicia Chilena, de Alejandra Matus), han llevado adelante una verdadera campaña pro libertad de expresión, independiente del sector político o ideológico que los medios particulares representen, denunciando su carencia en la constitucionalidad chilena, o reaccionando ante los abusos de la autoridad jurídica. El Programa Libertad de Expresión llevado adelante en la Universidad de Chile, por ejemplo, pretende que "al final de sus dos años de duración, se genere la figura del Defensor de la Libertad de Expresión y la publicación de un órgano de esta institución: El Observatorio de la Libertad de Expresión en Chile, que será quien registre y analice las dificultades, avances y atropellos en este campo"[17]. El tema en la Escuela de Periodismo de dicha Universidad adquiere tanta importancia que en el 2002 se ha constituido una agrupación con el rocambolesco nombre de "Periodistas por la libertad de expresión", que tiene por el "objeto de defender ese principio básico de la sociedad, así como la denuncia oportuna y pública de casos que vulneren el derecho de la ciudadanía a estar informados"[18].

En el campo de los investigadores, el asunto es más complejo: el uso de la libertad de expresión no sólo reviste al carácter inmediato de una carencia en la constitucionalidad chilena, sino que también se habla de una carencia social de libertad de expresión. En otras 
palabras, la concentración de los medios de comunicación en sectores dominantes (Sunkel)[19], junto a los procesos de globalización que tienden a derribar las barreras entre lo locas y lo extranjero, son vistos, por los investigadores, como factores determinante en la falta de expresión de diversos sectores sociales, falta de expresión que atenta, por omisión, al derecho a la libertad de expresión[20].

Podríamos citar otros ejemplos, pero creo que con estos basta para mostrar que, mucho más allá de lo que comúnmente se cree, la libertad de expresión se inserta dentro de un imaginario social amplio, con raíces históricas profundas que engarzan en lo más hondo de nuestro sentido común. Aquella sensibilidad republicana en la que la libertad de expresión encuentra cobijo, la articula con un conjunto de otros valores: democracia, tolerancia, diversidad, igualdad, y la pone frente a otra arena de anti valores: censura, intolerancia, desigualdad, totalitarimos, etcétera, cuya denuncia está a la base del discurso de Izquierda y en su consigna de defensa y representación de los sujetos más débiles de nuestra sociedad, o en su defecto, de los "sectores populares".

La necesidad de ésta libertad en nuestra Constitución, en consecuencia, encuentra eco en una matriz, en una sensibilidad, mucho más que una racionalizad definible por cuestiones puramente normativas. Por eso, porque apela a esta sensibilidad profunda de un tipo de modo de vida - a saber, el modo de vida republicano burgués - es que a la hora de su defensa, fuerzas que aparecen como antagónicas se aúnan. Bajo esta lógica (en la que opera la agrupación Periodista por la Libertad de Expresión), un periodista de izquierda podría eventualmente defender a otro de derecha si es que el poder político violenta sus libertades; es la libertad de expresión la que está siendo atacada. A sí mismo, un artistas que no comparta el pensamiento particular de otro puede salir también en su defensa si es que el último ha sido objeto de algún tipo censurado. En un ámbito más amplio, una super potencia podrá exigir a otros países aunar fuerzas contra un virtual enemigo en nombre de la defensa de las libertades[21]...

La libertad de expresión es un suelo profundo, pilar inamovible: placa tectónica de nuestra geología: removerla significa provocar un terremoto.

Constitución Política de la República de Chile, Capítulo Tres, Art. 19; 12, inciso tercero: "Toda persona natural o jurídica ofendida o injustamente aludida por algún medio de comunicación tiene el derecho a que su declaración o rectificación sea gratuitamente difundida, en las condiciones que la ley determine, por el medio de comunicación en que esa información hubiere sido emitida"[22].

El impedimento a expresarse en los medios modernos que, según Habermas, son los canales a través de los que la opinión pública se enfrenta al poder público[23], es el equivalente a la extirpación de la lengua en el Siglo XVIII. De ahí la cada vez mayor preocupación de los medios por dar tribuna a los auditores, a dejar que ellos se expresen directamente, sin interlocutores. Se dice: los medios están en deuda con sus espectadores, los medios se deben a su público, los medios deben retribuir al público. En la televisión, el éxito del reality show, del talk show, de los docu show y, en general, de los programas cuyos protagonistas son finalmente los propios públicos (El Termómetro, transmitido por Canal 11, la incorporación de los foros de opinión dentro del Noticiero de Canal 13, programas de ayuda directa como Buenas Tardes Eli, de Televisión Nacional, o el de los Matinales, etcétera) muestran esa tendencia manifiesta a convertir el medio en una tribuna, en un "libro de consultas y reclamos"[24]. Podríamos señalar que, si antes los medios se dedicaban a representar el habla ciudadana, ahora más bien se dedican a presentarla sin mediación alguna[25]. En la prensa escrita ocurre algo similar: la tendencia frecuenta al uso de encuestas revela esta preocupación. En un trabajo anterior he señalado que este uso de las encuestas por parte de los medios escritos llega a ser tan funcional que las encuestas son realizas ya para la prensa y, en algunos casos, a petición de ella con fines meramente propagandísticos[26]. La cercanía que el medio radial posee por sus características inherentes - la situación conversacional que establece con su oyente, la directa vinculación con la oralidad, su ubicuidad y transclacismo - la convirtió rápidamente en un precursor en este 
sentido, y en matriz modernizada y retomada por los otros medios para la configuración de un espacio de presentación de los ciudadanos en el proceso de mediación[27].

Los partidos políticos también se han insertado dentro de esta dinámica. La aparición de partidos ciudadanos (El Partido Por la Democracia, La Unión Demócrata Independiente) - que ya no responden a la matriz ideológica y que se ciñen al sistema de partidos norteamericano , y su notable éxito, muestra hasta qué punto la necesidad de dejar expresarse al ciudadano común y silvestre, en lo que quiera y en lo que le es más particular, es consustancial a la formación de un tipo de sociedad. Desideologizados ya estos partidos, los lenguajes se intercambian con facilidad y naturalidad: el cambio es traído ahora por los partidos llamados, en la antigüedad, conservadores. La Unión Demócrata Independiente - el partido que según Moulian representa a la oligarquía más tradicional de Chile - es ahora el Partido Popular, donde popular, a mi entender, deviene de que es el partido que "escucha a la gente".

La emergencia de partidos ciudadanos, partidos que escuchan a la gente, muestran un cambio en el tipo de electorado chileno. Señala Gustavo Martínez: "Me parece que la cultura política chilena ha experimentado transformaciones muy profundas desde la década de los 60 y de los 70 a la situación actual. Nuestra cultura política era marcadamente ideológica y ello generaba la posibilidad para la gente de hacer distinciones claras entre los partidos políticos relevantes del sistema de partidos existente hasta el quiebre democrático de 1973. (...) hoy vivimos una realidad diferente: la confrontación de proyectos de sociedad ha desaparecido"[28]. Según Martínez, los "partidos políticos en nuestro país han perdido prestigio y respeto en la opinión pública"[29] lo que habría aumentado el número de electores volátiles. Es este fenómeno el que habría hecho surgir partidos sin identificación ideológica, cuyo proyecto de desarrollo se basaría más en una pragmática, y cuya base estaría dada por una multiplicad de universos no representados (Sunkel), propios de una cultura heterodoxa - amas de casa, ecologistas, artistas, jóvenes, etcétera -, que serían sus potenciales votantes. La expresión encuentra su buzón de quejas en estos nuevos partidos populares [30].

La necesidad obliga a los cambios: la modernización del poder judicial chileno, la llamada reforma procesal penal, contiene una serie de cambios que apuntan a dar mayor expresión a los ciudadanos. La creación de una autoridad del poder judicial inédita en el derecho chileno, la del defensor público - titular de la defensoría penal pública - hace las veces de representante ante la ley de los imputados por delitos ante los tribunales de justicia[31]. El fiscal nacional es el máximo eslabón de la cartera del Ministerio Público, órgano que tiene por objeto investigar los delitos y perseguirlos penalmente en representación de la comunidad[32]; ambas instancias se confrontan en un "juicio oral y público"[33]; estas figuras, ausentes en nuestro sistema penal actual, implican un cambio sustantivo en la forma de aplicar justicia: en el sistema actual, la justicia tiene un carácter burocrático no azaroso: el proceso llevado a cabo mediante textos escritos no asegura, pero sí disminuye la posibilidad de que los juicios caigan en el dominio público, y lo que es más fundamental, ocultan a acusador y acusado detrás de sus firmas, detrás de sus figuras jurídicas. Salvo en los casos en que los medios de comunicación esperen a jueces o culpables a la salida de un careo o juicio, las personas que integran un proceso no tienen rostro. Por el contrario, con el nuevo sistema la justicia se vuelve mucho más espectacular: la aparición de nuevos actores como el fiscal nacional, el así llamado defensor público dan rostro a un proceso judicial que, salvo por los ministros de la corte suprema y por casos famosos, se mantenía anónimo para la opinión pública. Por otro lado, la publicidad de los juicios orales corporiza a los culpables y los inocentes, permitiendo observar y escuchar a los medios de comunicación casos judiciales comunes y silvestres, o de connotación social relativa y acorde con intereses mediáticos[34].

Cabe señalar que todos estos nuevos rituales expresan una necesidad que ya estaba instalada desde hace bastante tiempo en los medios de comunicación. La existencia, desde comienzos de los noventa, de una sección llamada no por casualidad el Tribunal del Pueblo en el programa Sábados Gigantes, y la actual operación de denuncia pública llevada a cabo por programas televisivos de participación ciudadana, son claros ejemplos de ese fenómeno. La entrada de lo público en los ministerios del estado chileno harían más transparente la justicia en la misma medida en que la populizan. 
Transformación del ethos intelectual: la libertad de expresión también ha influido en las formas en que se investiga la cultura moderna. Si bien esta materia es compleja y será resuelta en capítulos posteriores, cabe destacar aquí cómo esta obligación de escuchar que deviene de la necesidad de hablar de los ciudadanos con derechos también ha transformado profundamente la forma de abordar la investigación de la sociedad y la cultura. Así es como se ha pasado de un concepto de medios a un concepto de mediaciones (Jesús Martín Barbero), es decir, un concepto en que los estudios de objetos culturales ya no son definidos por patrones a priori que dicta el investigador, o que emanan desde la institucionalidad mediática, sino por la manera que estos objetos son percibidos y significados por los sujetos sociales y en la manera en que la institucionalidad mediática establece contratos de lectura con las comunidades. La influencia de la teoría de las mediaciones en los investigadores latinoamericanos ha sido definitoria para redefinir los objetos de estudio: éstos pondrán atención en las formas de percepción de las telenovelas, de la prensa sensacionalista y de otros productos tradicionalmente despreciados por el paradigma tradicional[35].

El habla. Derecho a expresarse. Es el hijo que exige su derecho a alegato frente al padre. La Mapuche que le quita el micrófono al Presidente de la República en pleno discurso. Los homosexuales que apelan a su derecho a manifestarse en una plaza pública. Los Nazis que impugnan un principio democrático para efectuar un congreso doctrinario. Es la geisha chilena, Anita Alvardo, "que tiene derecho a hablar". Lo prosaico elevado a la calidad de asunto de las más altas esferas del derecho y la moralidad pública. En todas sus variantes, las formas tradicionales del poder (del poder de la justicia, del poder de los medios de comunicación, del poder - saber), se desvanecen ante esta irrupción de una mayoría dispersa, de una mayoría cosmopolita y ruidosa que exige su llano derecho de hablar: es la gran "rebelión del coro"[36].

El ciudadano corriente es conciente que una de sus garantías básicas de ser individuo es el derecho a hablar. Ortega y Gasset se alarmaba, en La Rebelión de las Masas, por este irrespeto de los hombres modernos a no callar, a no saber escuchar la voz de los hombre superiores: "el hombre medio tiene las «ideas" más taxativas sobre cuanto acontece y debe acontecer en el universo. Por eso ha perdido el uso de la audición. ¿Para qué oír, si ya tiene dentro cuanto falta? Ya no es sazón de escuchar, sino, al contrario, de juzgar, de sentenciar, de decidir. No hay cuestión de vida pública donde no intervenga, ciego y sordo como es, imponiendo sus opiniones"[37].

El irrespeto de los hombres modernos por los hombre superiores, este "ruido" de las muchedumbres, es denunciado una y otra vez por las elites clásicas, alarmadas por el fenómeno irruptivo de los ciudadanos con derechos. Con hombres de estas características, un diálogo platónico ya no sería posible sin trenzarse a golpes con el interpelado. El "sabio" (Ossandón), la figura del maestro y el oyente, será reemplazada por los publicistas especializados en hacer surgir el parloteo disperso de las personas al dominio público, convirtiéndola en opinión pública[38].

Este tácito acuerdo entre diversos y distintos grupos haría pensar de que hoy como nunca la preocupación por la libertad de expresión muestra una mejoría en la calidad de vida. No habría desacuerdo en pensar la libertad de expresión como un bien necesario, y la izquierda haría gala de sendas cruzadas y grupos de defensa de la libertad de expresión, ubicándola como una bandera alzadas en el mástil más alto. Sin embargo, a partir de todo lo anterior, habría que preguntarse si la libertad de expresión - al menos en su significación actual - no es acorde con el sistema que la misma izquierda critica: a saber, el ethos individualista, consumista, "cosista", de escenificación de la vida privada, que tantas veces la hemos escuchado impugnar.

Y es que, como todo concepto naturalizado, se tendería a pensar que la libertad de expresión es un ideal que siempre ha pertenecido a la tradición de la izquierda. Es más: se tendería a pensar que siempre ha sido pensado como un ideal moral "positivo" para el progreso del país. Pareciera que este valor siempre ha estado ahí, en el centro de nuestra cultura nacional, en el centro de nuestras preocupaciones: en el primer párrafo de nuestra Constitución. 
Sin embargo, esto no fue siempre así:

Constitución Política de la República de Chile, 1925:

Art.1: El Estado de Chile es unitario. Su gobierno republicano y democrático representativo.

Art. 2: La soberanía reside esencialmente en la nación, la cual delega su ejercicio en las autoridades que la Constitución establece,

Art. 3: Ninguna persona o reunión de personas pueden tomar el título la representación del pueblo, arrogarse sus derechos, o hacer peticiones en su nombre. La infracción a este artículo es sedición[39].

$\mathrm{Ni}$ la libertad, ni los derechos individuales, ni la preocupación por el derecho a expresarse aparecen en los primeros párrafos de la anterior constitución. Por el contrario, las palabras claves aquí son unitario, nación y pueblo: estas tres, presentes en cada uno de los párrafos, muestran la inversión en la prioridad de los valores: mientras la libertad de expresión encaja en el discurso individualista, la unidad y la nación encajan en el discurso comunitario que tiene al concepto "pueblo" como ancla. No es casual que la constitución del 80 ponga patas arriba la episteme de su antecesora. Como tampoco, que la transformación más estructural y profunda de la izquierda en el Siglo XX se haya dado en el trascurso de esa época. Para entender dicho fenómeno, es necesario un recorrido histórico deconstructivo del discurso de distintos actores políticos e intelectuales relevantes, exhibir las fluctuaciones en sus discursos, sus contradicciones borradas por la inmediatez del presente. Falta aún mucho por descubrir (y criticar) del pasado más reciente para reciente de la izquierda, para recién comenzar a pensar en una alternativa.

[1] Derrida, Jaques: La retirada de la metáfora, Edit. Piados, España 1989. P. 37 - 38.

[2] Para comprender el concepto de "enunciado" de Foucault ver, entre otros: Deleuze, Gilles: Foucault, Edit. Piados, Argentina 1987.

[3] Una conocida empresa de telecomunicaciones tiene como concepto de campaña la "libre expresión".

[4] Lo a la mano, según Heidegger, refiere a un estado primario del Dasein como "estar ahí" con relación a las cosas del mundo, en palabra simples, refiere al estado irreflexivo, "natural" de ocupar las cosas. Ver Heidegger, Martín: Ser y tiempo, Edit. Universitaria, Santiago 1999.

[5] Ver Leal, Antonio: Gramsci: la ciudad futura, Edit. Documentas, Chile 1991.

[6] Esta interesante idea la extraje de su discurso de presentación de la novela de Diamela Eltit "Mano de obra".

[7] Una interpretación válida del concepto de "táctica" y de "estrategia" aparece, a mi modo de ver en De Certeau, Michel: La escritura de la historia. Edit. UIA, México, 1993.

[8] Constitución Política de la República de Chile, p 6.

[9] Ibid. p.1

[10] Ibid, p. 6.

[11] Entre otros, ver Brajnovic, Luka: Deontología Periodística, Edit. Eunsa, Espala 1978.

[12] El proyecto, más conocido como la "Casa de Vidrio", fue uno de los primeros de intervención de espacios urbanos y contó con el patrocinio del Fondo para la Difusión de la Cultura y las Artes (Fondart).

[13] Proyecto personal realizado por Luizo Vega. 
[14] El cómic se titula "Los Viajes de Massachussets", y fue realizado por Rodrigo Salinas con patrocinio de Fondart el año 2001 .

[15] Quizá el más polémico de todos los proyectos, pues terminó con la salida de la Directora de Fondart, Nidia Palma que acusó de "Censura" al Ministerio de Educación por presionar para el retiro del mismo. La obra se titula Prat, y fue dirigida por María José Parga y escrita por Manuela Infante.

[16] Ver Colegio de periodistas de Chile: Código de ética.

[17] Ver presentación del programa dirección en

http://www.periodismo.uchile.cl/libertaddeexpresion/presentacion/index.html

[18] Ver en dirección Internet: http://www.periodismo.uchile.cl/noticias/2002/batalla.html

[19] Sunkel, Guillermo y Esteban Geofroy: Concentración económica de los medios de comunicación. Edit. LOM, Chile 2001.

[20] Ver Rebolledo, Loreto: Percepción de los sectores populares sobre la libertad de expresión PP 13, en dirección Internet: http://www.periodismo.uchile.cl/libertaddeexpresion/documentos/index.html

[21] Obviamente me refiero al discurso del presidente norteamericano, George Bush, que inaugura la operación "Libertad Duradera", contra la organización terrorista Al Queda.

[22] Constitución Política de... Op.Cit p.6.

[23] Ver Habermas, Jurgen: Historia y crítica de la opinión pública, Edit. Gustavo Gili, España, 1981.

[24] Ver Acevedo, Jorge: Los talk shows: fascinación o rechazo, en www.felafacs.org.

[25] Con respecto a este tema, aparte del libro de Habermas se puede consultar un interesante articulo aparecido en la revista electrónica de la Universidad Nacional de Rosario (Argentina) titulado Opinión Pública y Escenarios Mediales, escrito por Sandra Valdettaro. La autora no sólo realiza un prolijo análisis de la obra de Habermas ya citada, sino que propone trayectorias para los futuros espacios públicos. Valdettaro, Sandra: Opinión Pública y Escenarios Mediales, en www.unr.edu.ar.

[26] Ver Ruiz, Felipe: La encuestodependencia en la prensa chilena y Cumsille, Guillermo: Algunas precisiones sobre las encuestas electorales. Biblioteca Escuela de Periodismo, Universidad de Chile.

[27] El caso de la radio será analizado posteriormente, por ahora, podemos citar a Gutiérrez, Paulina y Munizaga, Giselle: Radio y cultura popular de masas, Edit. Ceneca, Chile 1983.

[28] Martínez, Gustavo: Diversos votantes, en ¿Cómo ganar una elección? varios autores. Edit. Konrad Adenauer, Chile 2000. pp. $56-57$.

[29] Ibid. p. 59.

[30] Ver Sunkel, Guillermo: Razón y pasión en la prensa popular, Edit. Ilet, Santiago 1985.

[31] Código Procesal Penal, Ley 19.718.

[32] Ley 19.640.

[33] Código Procesal Penal, Art. No.1.

[34] La corporización del culpable nos recuerda las reflexiones de Foucault a propósito del juicio a Damiens: "notemos que el último suplemento de la muerte penal ha sido un velo del luto. El condenado no tiene ya que ser visto. (...) desaparece, pues, en los comienzos del Siglo XIX, el gran espectáculo de la pena física". Podemos sospechar que, el aprovechamiento como espectáculo mediático de la reforma procesal penal podría no sólo volver público el juicio sino que, a través del mismo, volvernos a los tiempos de las "penas públicas", como en efecto sucede en países en que se mal aplica la justicia oral - pública. Ver Foucault, Michel: Vigilar y Castigar, Edit. Siglo XXI, España 2001.

[35] Ver Martín - Barbero, Jesús: De los medios a las mediaciones, Edit. Gustavo Gili, España 1991.

[36] La rebelión del coro, metáfora que da título a esta investigación, es usada por Ortega y Gasset: "La muchedumbre, de pronto, se ha hecho visible, se ha instalado en los lugares preferentes de la sociedad. Antes, si existía, pasaba inadvertida, ocupaba el fondo del escenario social; ahora se ha adelantado a las baterías, es ella el personaje principal. Ya no hay protagonistas: sólo hay coro". El concepto, como señala Sunkel, se ha vuelto popular para designar la 
irrupción del sujeto popular no representado. Ver Sunkel, Guillermo: Razón y... Op.Cit p. 39. y Ortega y Gasset, José: La rebelión de las masas, Edición electrónica: http://idd00qaa.eresmas.net/ortega, p.13

[37] Ibid. p. 29.

[38] Ossandón se refiere al concepto "publicista" empleado por Habermas. Ver Ossandón, Carlos: El crepúsculo de los sabios y la irrupción de los publicistas...Op. cit. p. 24 ..

[39] Constitución Política de la República de Chile (1925). 